\title{
Taxation on Land Value and Development When There Are Negative Externalities from Development
}

\author{
Jyh-Bang Jou • Tan Lee
}

(C) Springer Science + Business Media, LLC 2007

\begin{abstract}
This article employs a real options framework to investigate the design of taxation on both land value and development in a competitive real estate market. We assume that developed properties reduce open space, and thereby harm urban residents. However, ignoring this negative externality, landowners will develop properties sooner than is socially optimal. A regulator can correct this tendency by imposing a positive tax on development or a negative tax on land value. Alternatively, the regulator can implement both instruments simultaneously, in which case an increase in the tax rate on development will be accompanied by an increase in the tax rate on land value, and vice versa.
\end{abstract}

Keywords Negative externality $\cdot$ Real options $\cdot$ Optimal taxation

\section{Introduction}

Several recent articles investigate how taxation on the market value of vacant land and on the costs to develop such land affects choices regarding the timing of development. However, few studies discuss the normative aspect of these policy

\footnotetext{
J.-B. Jou

Graduate Institute of National Development, National Taiwan University, No. 1 Roosevelt Rd. Sec. 4, Taipei 106 Taiwan, Republic of China e-mail: jbjou@ntu.edu.tw

T. Lee $(\bowtie)$

Department of International Business, Yuan Ze University, No. 135 Yuan-Tung Rd., Chung-Li, Taoyuan 320 Taiwan, Republic of China e-mail: tanlee@saturn.yzu.edu.tw
} 
instruments, that is, why the regulator employs them in the first place. To the best of our knowledge, the only theoretical article that focuses on this issue is Anderson (1993). ${ }^{1}$

Anderson constructs a non-stochastic model in which an owner of vacant land extends benefits to urban residents through the provision of open space. Modeling these benefits as an increasing function of the cash inflow received by the owner, he shows that the regulator can induce the landowner to delay developing property through the use of a Pigouvian subsidy. In this article we investigate an issue similar to Anderson (1993), but different from Anderson, we derive the policy-maker's optimal property taxation in a stochastic environment. ${ }^{2}$

Specifically, we consider a perfectly competitive real estate industry that consists of homogeneous landowners. ${ }^{3}$ We assume that developed properties reduce open space and thereby harm urban residents. Following Anderson (1993), we assume that this external cost increases as landowners receive more cash flow. Landowners will ignore this externality, and will therefore develop properties sooner than is socially optimal. The regulator can correct this tendency by implementing a single instrument such as a positive tax on land development or a negative tax (i.e., a subsidy) on land value. In the first case, the regulator should increase the tax rate on development if the negative externality rises; in the second case, the regulator should decrease the subsidy to land value if the negative externality falls, demand uncertainty increases, demand for developed properties is expected to grow at a higher rate, or the discount rate decreases. Alternatively, the regulator can simultaneously implement both policy instruments. In this case, if the regulator increases the tax rate on development, he should also increase the tax rate (i.e., decrease the subsidy rate) on land value, and vice versa.

Our article is closely related to the real options literature such as Dixit (1991) and especially Grenadier (1995) — while both of these papers abstract from the issue of externalities, they solve the competitive equilibrium associated with the maximization problem faced by a social planner. ${ }^{4}$ Similar to Grenadier, we assume that land development requires an initial lump sum construction cost. At any point in time, landowners who have developed properties will rent their properties. The market clearing condition requires that the spot price adjusts so that current supply equals stochastic demand. If the industry's prospects become sufficiently favorable, new developers will find it optimal to develop properties. The decision to enter the real estate industry is analogous to the decision to exercise a call option on a real estate asset where the exercise price is the cost of development: when the value of entering

\footnotetext{
${ }^{1}$ Irwin and Bockstael (2004) also consider externalities involving open space. However, they focus on how a "smart growth" policy (such as a policy that preserves open space) associated with these externalities affects planned development timing rather than on the design of optimal property taxation.

${ }^{2}$ Anderson (1993) suggests that land development imposes external costs associated with increased traffic congestion, higher density, and attendant problems.

${ }^{3}$ In this article we assume that landowners are also developers. We therefore use both terms interchangeably in what follows.

${ }^{4}$ See Capozza and Li (1994), who also employ real options analysis. However, they focus on a representative landowner and investigate how taxation on property values both before and after development affects the landowner's choices regarding development timing and capital intensity.

글 Springer
} 
the industry rises to the level of the development cost, new developers will enter such that no excess profits will exist.

When property development exhibits negative externalities, however, the optimal development timing decision for the competitive real estate industry and that for the centralized economy are different because the former will ignore the negative externality, while the latter will internalize it. We assume that the decision rule for each is determined by a different kind of social planner: the "naive" social planner ignores the externality and solves for the competitive equilibrium, and the "sophisticated" social planner internalizes the externality and solves for the centralized economy. We then investigate how a regulator may employ a positive tax on development and/or a negative tax on land value to induce the naive social planner to develop properties in accordance with the timing that the sophisticated social planner would choose.

In addition to analyzing the design of optimal property taxation, we also investigate how property taxation affects a developer's choice of development timing in the competitive equilibrium. We find that a developer will delay development if either the tax rate on land value decreases or the tax rate on development increases. Our results therefore provide further support to Anderson (1986), who abstracts from uncertainty. Given our article focuses only on the development timing choice, our results cannot be directly compared to those articles that allow for the simultaneous choices concerning both the timing and the density (or capital intensity) of land development, such as Arnott (2005), Arnott and Lewis (1979), McFarlane (1999), and Turnbull (1988a, b).

The remainder of this article is organized as follows. "Basic Assumptions" section presents the assumptions in our model. "Optimal Development Timing Choices" section solves the development timing choice for both the competitive real estate industry and the centralized economy. In particular, we investigate how taxation on land value and development affects the timing choice for developers in the real estate industry. "Optimal Taxation on Land Value and Development" section reports the comparative-statics results on how various exogenous forces affect the optimal levels of these two taxation instruments. "Numerical Analysis" section employs plausible parameter values to do numerical analysis. The last section concludes with caveats and suggestions for future research.

\section{Basic Assumptions}

In this section we build a model that extends Grenadier (1995). Consider a competitive real estate industry with a large number of landowners, where each landowner owns one unit of vacant land. ${ }^{5}$ We assume that the units are small enough and the number of landowners are large enough such that the current total supply of developed properties may be represented as a continuum whose mass at time $t$ is $Q(t)$.

\footnotetext{
${ }^{5}$ The model will yield identical results if developers are permitted to own more than one unit of vacant land, provided no single developer yields significant market power.
} 
At each point in time, the rent per unit of developed property, $P_{d}(t)$, which evolves such that it clears the market, is of the constant-elasticity form

$$
P_{d}(t)=X(t) Q(t)^{b-1}
$$

where $1>b>0$ and $X(t)$ represents a multiplicative demand shock that evolves according to a geometric Brownian motion:

$$
d X(t)=\alpha X(t) d t+\sigma X(t) d \Omega(t)
$$

where $\alpha$ is the instantaneous expected percentage change in $X(t)$ per unit time, $\sigma$ is the instantaneous standard deviation per unit time, and $d \Omega(t)$ is an increment of a standard Wiener process. Such a market is thus characterized by evolving uncertainty in the state of demand for the developed property. We assume that development, which reduces open space, harms urban residents. Similar to Anderson (1993), we assume that the external cost increases as the cash flow from developed properties increases. Consequently, from the viewpoint of a "sophisticated" social planner who takes this externality into account, the marginal value of an additional developed property is reduced to

$$
P_{c}(t)=(1-a) P_{d}(t), 0<a<1,
$$

where $a$ denotes the size of the external effect. ${ }^{6}$

Landowners may add to the supply of developed properties by incurring a onetime construction cost of $K$ that is proportional to the quantity of new units of developed property supplied. We assume that landowners can construct buildings instantly, and thus they earn an instantaneous profit per unit time of $P_{d}(t)$ per unit of developed property. ${ }^{7}$ However, the construction costs, once incurred, are assumed to be irreversibly committed thereafter.

Like Grenadier (1995), we seek to construct a competitive equilibrium in which developers have rational expectations. Such an equilibrium involves the simultaneous determination of developers' rents and entry strategies, assuming that these developers ignore the negative externality from development. Development strategies, the rent process, and expectations are all interdependent and must be mutually consistent in equilibrium. Developers choose strategies so as to maximize the discounted present value of profits less development costs, given their expectations concerning the probability distribution governing the rent of developed property. These strategies, together with the exogenous demand shocks, determine the actual realization of the rent and supply in the real estate industry. If expectations turn out to be rational, then the rent process the developers use to form their strategies and the actual rent process will be the same function of the current state variables. Finally, to be a competitive equilibrium, the present discounted value of equilibrium profits at any point of entry must equal the cost of development at that time.

\footnotetext{
${ }^{6} \mathrm{Here}$ and in what follows, we use the subscripts " $d$ " and " $c$ " to represent the decentralized economy and the centralized economy, respectively.

${ }^{7} \mathrm{We}$ do not consider the time-to-build problem. See Grenadier (2000) for a thorough discussion of this issue.

Springer
} 
Such a rational expectations competitive equilibrium can be determined as the solution to a maximization problem. As in Lucas and Prescott (1971) or Dixit (1991), the equilibrium evolves as if to maximize the expected present discounted value of social welfare in the form of consumer surplus. That is, the equilibrium path of rents and quantities of developed properties can be derived from the perspective of a "naive" social planner who ignores the negative externality from development.

The problem for the naive social planner is to choose the path of new supply of developed properties so as to maximize the value of the flow of consumer surplus. This is precisely the same as choosing the path of $Q(t)$. The total flow rate of social surplus in the view of the naive social planner, $S_{d}[X(t), Q(t)]$, is equal to the area under the following demand curve:

$$
S_{d}[X(t), Q(t)]=\int_{0}^{Q(t)} X(t) q^{b-1} d q=\frac{X(t) Q(t)^{b}}{b} .
$$

The sophisticated social planner, in contrast, will internalize the externality before developing properties, and thus he takes the total flow rate of social surplus to be given by

$$
S_{c}[X(t), Q(t)]=\frac{(1-a) X(t) Q(t)^{b}}{b} .
$$

We assume that developers are risk neutral, and thus the appropriate discount rate is the risk-free interest rate, $\rho$. This seemingly restrictive assumption can be relaxed by adjusting the drift rate, $\alpha$, by a risk premium in the way of Cox and Ross (1976).

When property development exhibits negative externalities as shown in Eq. 1', then the market outcome will be inefficient. To correct this, a regulator can adopt policies that include density ceiling control (Lee and Jou 2007) or Pigouvian taxes such as property taxes, building fees, and entitlement fees. We focus on two kinds of property taxation, a tax on the market value of vacant land and a tax on the development costs, but abstract from the other instruments. We assume that these two policy instruments are already set before vacant land is developed. Denote by $\tau$ the tax rate on land value and $u$ the tax rate on development, both of which are constant over time. Note that $\tau$ can be either positive or negative (i.e., a subsidy), while $u$ is always positive.

By following the literature that applies noncooperative dynamic games to environmental management (see, e.g., Jou 2001, 2004), we model land use regulation as a hierarchical game. Developers compete to enter the real estate industry at the lower level of the game. At the upper level the game takes the form of a Stackelberg game in which a regulator acts as the leader and a developer acts as the follower. Anticipating the timing chosen by the developer, the regulator should set a tax on development and/or a negative tax on land value to induce the developer to choose the socially optimal level of development timing.

\section{Optimal Development Timing Choices}

In this section we investigate how to design optimal taxation on land value and development by sequentially analyzing the behavior of both the naive social planner and 
the sophisticated social planner. We show that these planners make different choices regarding the timing of development, because the former ignores the externality while the latter internalizes it.

\section{The Choice of the Naive Social Planner}

The maximization problem faced by the naive social planner has two state variables, $X(t)$ and $Q(t)$. The former evolves exogenously, whereas the latter is subject to control. Suppose that we start at time 0 with $X(0)=X$ and $Q(0)=Q$ given. The problem for the naive social planner is to choose the path $Q(t)$ optimally. As in Pindyck (1988), we approach the solution to this problem by examining the incremental development decision faced by the naive social planner. The opportunity to invest in an additional unit of developed property is analogous to a perpetual American call option. The underlying asset is the value of an extra unit of developed property and the exercise price is the cost of constructing this unit, denoted by $K$.

Therefore, the solution to the naive social planner's development timing problem involves two steps. First, the value of an extra unit of developed property must be determined. Second, the value of the option to invest in this unit must be determined, together with the decision rule for exercising this option. This decision rule is then the solution to the problem of those developers waiting to enter the real estate industry.

The value of an additional developed property is the present value of the expected flow surplus from this unit, denoted by $\Delta G_{d}(X, Q)$, which is equal to

$$
\Delta G_{d}(X, Q)=E \int_{0}^{\infty} e^{-\rho t} \frac{\partial S_{d}(X(t), Q)}{\partial Q} d t=\frac{X Q^{b-1}}{(\rho-\alpha)} .
$$

Having valued this marginal unit, we can now value the option to invest in this unit, denoted by $\Delta F_{d}(X, Q)$. Using standard contingent-claim valuation methods, it is easy to show that $\Delta F_{d}(X, Q)$ satisfies the following differential equation:

$$
\frac{1}{2} \sigma^{2} X^{2} \frac{\partial^{2} \Delta F_{d}(\cdot)}{\partial X^{2}}+\alpha X \frac{\partial \Delta F_{d}(\cdot)}{\partial X}-(\rho+\tau) \Delta F_{d}(\cdot)=0
$$

Equation 5 has an intuitive interpretation: if $\Delta F_{d}$ is an asset's value, then the normal return $\rho \Delta F_{d}$ equals the expected capital gain given by

$$
\frac{E\left(d \Delta F_{d}\right)}{d t}=\alpha X \frac{\partial \Delta F_{d}}{\partial X}+\frac{1}{2} \sigma^{2} X^{2} \frac{\partial^{2} \Delta F_{d}}{\partial X^{2}},
$$

minus taxation on land value denoted by $\tau \Delta F_{d}$.

The solution to Eq. 5 is given by ${ }^{8}$

$$
\Delta F_{d}(X, Q)=A_{1 d}(Q) X^{\beta_{1 d}}+A_{2 d}(Q) X^{\beta_{2 d}},
$$

\footnotetext{
${ }^{8}$ Given this functional form for $\Delta F_{d}$, we may derive the distribution of equilibrium rent, $P_{d}(t)$, in Eq. 2. We do not present the results here because they are quite messy, but they are available from the authors upon request. See also Grenadier (1995), who derives the distribution of the equilibrium rent in a model similar to ours.
} 
where $A_{1 d}$ and $A_{2 d}$ are constants to be determined, and $\beta_{1 d}$ and $\beta_{2 d}$ are the large and small roots, respectively, of the quadratic equation given by

$$
\phi(\beta)=-\frac{1}{2} \beta(\beta-1)-\alpha \beta+\rho+\tau=0 .
$$

Consequently, they are equal to

$$
\begin{aligned}
& \beta_{1 d}=\frac{1}{2}-\frac{\alpha}{\sigma^{2}}+\sqrt{\left(\frac{1}{2}-\frac{\alpha}{\sigma^{2}}\right)^{2}+\frac{2(\rho+\tau)}{\sigma^{2}}}, \\
& \beta_{2 d}=\frac{1}{2}-\frac{\alpha}{\sigma^{2}}-\sqrt{\left(\frac{1}{2}-\frac{\alpha}{\sigma^{2}}\right)^{2}+\frac{2(\rho+\tau)}{\sigma^{2}}} .
\end{aligned}
$$

As is well known in the real options literature (Dixit and Pindyck 1994), when uncertainty arises, the development rule takes the form whereby landowners will not develop until the demand shock, $X$, rises to some threshold level, $X_{d}$. This critical level, together with $A_{1 d}(Q)$ and $A_{2 d}(Q)$ in Eq. 7, is solved from the boundary conditions given by

$$
\begin{gathered}
\lim _{X \rightarrow 0} \Delta F_{d}(X, Q)=0 \\
\Delta F_{d}(X, Q)=\Delta G_{d}(X, Q)-(1+u) K, \\
\frac{\partial \Delta F_{d}(X, Q)}{\partial X}=\frac{\partial \Delta G_{d}(X, Q)}{\partial X} .
\end{gathered}
$$

Equation 10 is the limit condition, which states that the option value of waiting is worthless as the demand shock approaches zero. Eq. 11 is the value-matching condition, which states that at the optimal development timing choice, developers should be indifferent as to whether vacant land is developed or not. Eq. 12 is the smooth-pasting condition, which requires that developers not obtain any arbitrage profits from deviating from the optimal development timing choice. Solving Eqs. 10 through 12 simultaneously yields

$$
\begin{gathered}
A_{2 d}(Q)=0 \\
A_{1 d}(Q)=\frac{(1+u) K}{\left(\beta_{1 d}-1\right)}\left[\frac{\beta_{1 d}(\rho-\alpha)(1+u) K}{\left(\beta_{1 d}-1\right)}\right]^{-\beta_{1 d}} Q^{-\beta_{1 d}(1-b)}, \\
X_{d}(Q)=\frac{\beta_{1 d}(1+u)(\rho-\alpha) K}{\left(\beta_{1 d}-1\right)} Q^{1-b}
\end{gathered}
$$


Using the supply trigger equation, Eq. 15, both equilibrium supply, $Q^{*}(t)$, and equilibrium rent, $P_{d}^{*}(t)$, can be expressed as a function of the exogenous state variable:

$$
Q^{*}(t)=\max \left[\left(\frac{\left(\beta_{1 d}-1\right)}{\beta_{1 d}(1+u)(\rho-\alpha) K}\right)^{\frac{1}{1-b}} \cdot \sup \left\{X(s)^{\frac{1}{1-b}}, 0 \leq s \leq t\right\}, Q(0)\right],
$$

$$
P_{d}^{*}(t)=X(t) Q^{*}(t)^{b-1} .
$$

Proposition 1, stated below, indicates how changes in both the tax rate on land value and the tax rate on development affect a landowner's choice regarding the timing of development in a competitive equilibrium.

Proposition 1 A developer will delay development ( $X_{d}$ will increase) if $(a)$ demand uncertainty is greater ( $\sigma$ increases), $(b)$ the tax rate on land value decreases $(\tau$ decreases), and (c) the property-tax rate on development increases ( $u$ increases). $(d)$ Given that the tax rate on land value is non-negative, a developer will develop sooner if demand for developed property is expected to grow at a higher rate ( $\alpha$ increases). (e) A developer may develop earlier, later, or at the same schedule if the discount rate increases ( $\rho$ increases).

\section{Proof See Appendix A.}

The result of Proposition 1(a), i.e., uncertainty delays development, is consistent with the standard result of the real options literature (Dixit and Pindyck 1994). The result of Proposition 1(b) follows because a decrease in the tax rate on land value raises the option value from waiting, and thus leads to a delay in development. This result is in line with Anderson (1986), who abstracts from uncertainty but also focuses on only the development timing decision. The result of Proposition 1(c) follows because an increase in the tax rate on development decreases the net value from developing properties, and thus retards development. The results of Propositions 1(b) and 1(c) are not directly comparable with the results of articles such as Arnott (2005), Arnott and Lewis (1979), McFarlane (1999), and Turnbull (1988a, b) because these articles allow landowners to choose the development timing and also the scale (or capital intensity) of development. However, these studies reach the same conclusion as we do in this article when they treat development scale as exogenously given. ${ }^{9}$

The rationale for Proposition 1(d) is as follows. If the regulator does not impose any taxation on land value, then an increase in the growth rate of the demand for developed properties accelerates development, which is the standard result of the real options literature (Dixit 1991). When the regulator imposes a tax on land value, then we must add the effect stated in Proposition 1(a), i.e., a positive (negative) tax

\footnotetext{
${ }^{9}$ Whether their result is consistent with our result when landowners are allowed to vary the scale (or the capital intensity) of development depends on whether the demanded density is increasing over time. 
rate on land value accelerates (delays) development, thus reinforcing (offsetting) the effect mentioned above.

Our result stated in Proposition 1(e), which indicates that an increase in the discount rate has an indeterminate effect on the choice of development timing, resembles that of Bar-Ilan and Strange (1999). The ambiguous effect follows because of two mutually conflicting forces: first, the future rewards are discounted more, thus delaying development; second, the development costs are also discounted more, thus accelerating development.

The Choice of the Sophisticated Social Planner

Consider the case of the centralized economy in which a sophisticated social planner internalizes the negative externality before choosing the development timing. Following similar arguments to those above for the naive social planner, we derive the sophisticated social planner's marginal value of an additional unit of developed property and value of the option to delay development of this unit as given, respectively, by

$$
\begin{gathered}
\Delta G_{c}(X, Q)=\frac{(1-a) X Q^{b-1}}{(\rho-\alpha)}, \\
\Delta F_{c}(X, Q)=A_{1 c}(Q) X^{\beta_{1 c}}+A_{2 c}(Q) X^{\beta_{2 c}},
\end{gathered}
$$

where $A_{1 c}(Q)$ and $A_{2 c}(Q)$ are constants to be determined, and $\beta_{1 c}$ and $\beta_{2 c}$ are equal to

$$
\begin{aligned}
& \beta_{1 c}=\frac{1}{2}-\frac{\alpha}{\sigma^{2}}+\sqrt{\left(\frac{1}{2}-\frac{\alpha}{\sigma^{2}}\right)^{2}+\frac{2 \rho}{\sigma^{2}}}, \\
& \beta_{2 c}=\frac{1}{2}-\frac{\alpha}{\sigma^{2}}-\sqrt{\left(\frac{1}{2}-\frac{\alpha}{\sigma^{2}}\right)^{2}+\frac{2 \rho}{\sigma^{2}}} .
\end{aligned}
$$

The optimal development timing is therefore given by

$$
X_{c}(Q)=\frac{\beta_{1 c}(\rho-\alpha) K}{\left(\beta_{1 c}-1\right)(1-a)} Q^{1-b} .
$$

Proposition 2 follows from Eq. 15'.

Proposition 2 The sophisticated social planner will delay development if (a) demand uncertainty is greater ( $\sigma$ increases), $(b)$ the size of the negative externality is larger (a increases), or (c) demand for developed properties is expected to grow at a lower rate ( $\alpha$ decreases). (d) The social planner may develop sooner, later, or remain at the same schedule as the discount rate $(\rho)$ increases.

Proof See Appendix B.

The results of Proposition 2(a), 2(c), and 2(d) are similar to their counterparts in Proposition 1. The result of Proposition 2(b) follows because the sophisticated social 
planner will delay development so as to mitigate the harmful effect of property development on the welfare of urban residents when the size of the negative externality is greater.

\section{Optimal Taxation on Land Value and Development}

Substituting $\tau=u=0$ into $X_{d}(Q)$ in Eq. 15 and comparing the result with $X_{c}(Q)$ in Eq. 15 ' yields $X_{d}(Q)<X_{c}(Q)$. This suggests that, in the absence of any taxation, landowners will develop properties sooner than is socially optimal. The regulator can employ a tax on land value and/or a tax on development to correct this tendency. The optimal taxation policy may be derived by Eq. $X_{d}(Q)$ in Eq. 15 and $X_{c}(Q)$ in Eq. 15', and several comparative-statics results can be derived from this equality, as indicated by Proposition 3 stated below.

Proposition 3 (a) Suppose that a regulator treats taxation on development as given. The regulator should decrease the optimal tax rate on land value, denoted by $\tau^{*}$, if the size of the external effect is greater (a increases). If the regulator initially taxes (subsidizes) land value, then the regulator should decrease the optimal tax (subsidy) rate on land value if demand uncertainty is greater ( $\sigma$ increases), future demand for developed properties is expected to grow at a higher rate ( $\alpha$ increases), and the discount rate is lower ( $\rho$ decreases). (b) Suppose that the regulator treats taxation on land values as given; the impacts of $a, \sigma, \alpha$, and $\rho$ on the optimal tax rate on development, denoted by $u^{*}$, will be just the opposite of their counterparts stated in (a). (c) Suppose that a regulator simultaneously implement taxes on both land value and development; the regulator should increase the tax rate on land value if he increases the tax rate on development, and vice versa.

\section{Proof See Appendix C.}

The results of Proposition 3 are the main contribution of this article, and thus deserve a thorough explanation. First, as the negative externality becomes more severe ( $a$ increases), the regulator should either decrease the tax rate on land value or increase the tax rate on development. As a result, developers in the competitive real estate industry will be induced to delay development, as shown by Propositions 1(b) and 1(c), respectively. Second, when demand uncertainty is greater, both a landowner in the competitive real estate industry and the sophisticated social planner will delay development. If the regulator does not impose any tax on land value, then the impact will be the same for both. If the regulator initially taxes (subsidies) land value, then the incentive to delay development will be lower (higher) for the landowner than for the sophisticated social planner. Consequently, the regulator should either decrease the tax (subsidy) rate on land value or increase (decrease) the tax rate on development so as to induce the developer to delay (accelerate) development such that the timing decision matches the timing chosen by the sophisticated social planner. Similar reasoning can be used to explain why the regulator should implement the same policy if either future demand for developed properties is expected to grow at a higher rate or the discount rate declines. 
The rationale for Proposition 3(c) is better explained by considering the polar case in which the regulator does not implement any tax on land value. In such a case, we find that the optimal tax rate on development is given by

$$
u^{*}=\frac{1}{1-a}-1
$$

If the regulator raises the tax rate on development from the level shown by Eq. 18, then developers in the real estate industry will develop later than is socially optimal, as shown by Proposition 1(c). To restore the social optimum, the regulator must tax land value so as to induce developers to develop sooner, as shown by Proposition 1 (b). Consequently, the policy of taxing on land value is complementary to the policy of taxation on development.

In the other polar case, where the regulator does not implement any tax on development, then the optimal policy is to grant a subsidy rate to land value. As shown by Proposition 1(b), this policy will then induce landowners to delay development such that the timing schedule matches the timing chosen by the sophisticated social planner.

\section{Numerical Analysis}

We employ numerical analysis to make the theoretical results of the last section more vivid. We begin by establishing a set of benchmark parameter values. We assume that developers in a competitive real estate industry incur a cost of $\$ 1$ to install one unit of capital stock $(K=1)$. Additionally, developers face an industry demand function with a constant elasticity, $1 /(1-b)$, equal to 3.33 (i.e., $b=0.7)$. The demandshift factor, $X$, is expected to grow $2 \%$ per year, $\alpha=0.02$, the volatility of this growth rate, $\sigma$, is equal to $20 \%$ per year, and the (risk-free) discount rate, $\rho$ is equal to $5 \%$ per year. Due to the externality of developed properties, the rent per unit of developed property is reduced by $10 \%(a=0.1)$ from the point of view of a sophisticated social planner. Initially, the supply of developed properties is

Table 1 Option value of waiting, investment value, development trigger, and optimal taxation on both land value and development when the size of externality changes

\begin{tabular}{|c|c|c|c|c|c|}
\hline \multirow[t]{2}{*}{ Parameters } & \multicolumn{5}{|c|}{ Variation in $a$} \\
\hline & 0 & 0.05 & 0.1 & 0.15 & 0.2 \\
\hline$X_{c}$ & 0.0816 & 0.0859 & 0.0907 & 0.0960 & 0.1020 \\
\hline$u^{*}$ & $50.4 \%$ & $58.3 \%$ & $67.1 \%$ & $76.9 \%$ & $88.0 \%$ \\
\hline$\tau^{*}$ & $1.402 \%$ & $0.924 \%$ & $0.499 \%$ & $0.118 \%$ & $-0.224 \%$ \\
\hline
\end{tabular}

Benchmark case: $b=0.7, a=0.1, \alpha=0.02, \sigma=0.2, \rho=0.05, \tau=0.05, u=0.2, Q=1, K=1, \Delta F_{d}=0.9708, \Delta G_{d}=$ 2.1708, $X_{d}=0.0651, X_{c}=0.0907, \tau^{*}=0.499 \%, u^{*}=67.1 \%$. We do not report values for endogenous variables if they are invariant to changes in exogenous variables, i.e., if they are equal to those of the benchmark case 
Table 2 Option value of waiting, investment value, development trigger, and optimal taxation on both land value and development when the demand volatility changes

\begin{tabular}{|c|c|c|c|c|c|}
\hline \multirow[t]{2}{*}{ Parameters } & \multicolumn{5}{|c|}{ Variation in $\sigma$} \\
\hline & 0.1 & 0.15 & 0.2 & 0.25 & 0.3 \\
\hline$\Delta F_{d}$ & 0.5413 & 0.7418 & 0.9708 & 1.2271 & 1.5111 \\
\hline$\Delta G_{d}$ & 1.7413 & 1.9418 & 2.1708 & 2.4271 & 2.7111 \\
\hline$X_{d}$ & 0.0522 & 0.0583 & 0.0651 & 0.0728 & 0.0813 \\
\hline$X_{c}$ & 0.0667 & 0.0775 & 0.0907 & 0.1062 & 0.1239 \\
\hline$u^{*}$ & $53.1 \%$ & $59.6 \%$ & $67.1 \%$ & $75.0 \%$ & $82.9 \%$ \\
\hline$\tau^{*}$ & $0.623 \%$ & $0.558 \%$ & $0.499 \%$ & $0.452 \%$ & $0.415 \%$ \\
\hline
\end{tabular}

Benchmark case: same as Table 1

normalized to be equal to one unit, $Q=1$, and the regulator imposes a $5 \%$ tax rate on land value and a $20 \%$ tax rate on development $(\tau=0.05, u=0.2)$.

Given these benchmark parameter values, Tables 1, 2, 3, 4, 5, and 6 report the results for several endogenous variables: for the decentralized economy, the option value of investing in an additional unit of developed property is equal to 0.9708 ( $\left.\Delta F_{d}=0.9708\right)$, the value of this additional unit is equal to $2.1708\left(\Delta G_{d}=2.1708\right)$, and the development trigger, $X_{d}$, is equal to 0.0651 . Note that this trigger is lower than that for the centralized economy, $X_{c}$, which is equal to 0.0907. To induce landowners to delay development (until the timing chosen by the sophisticated social planner), the regulator should either increase the tax rate on development, $u^{*}$, to $67.1 \%$, or decrease the tax rate on land value, $\tau^{*}$, to $0.499 \%$.

Tables 1, 2, 3, 4, 5, and 6 also report the effects of the size of the externality $(a)$ demand uncertainty $(\sigma)$, the expected growth rate of the demand-shift factor $(\alpha)$, the discount rate $(\rho)$, the tax rate on land value $(\tau)$, and the tax rate on development $(u)$ on the endogenous variables, holding all the other parameter values constant. ${ }^{10}$ These results are consistent with those of Propositions 1, 2, and 3. First, consider an increase in the size of the externality. As the negative externality from development becomes greater ( $a$ increases), the sophisticated social planner will wait for a better state to develop ( $X_{c}$ increases). An increasing negative externality also leads the regulator to either increase the optimal tax rate on development $\left(u^{*}\right)$ or reduce the optimal tax rate on land value $\left(\tau^{*}\right)$.

Consider next an increase in the demand volatility $(\sigma)$. For the decentralized economy, the option value of investing in an additional unit of developed property $\left(\Delta F_{d}\right)$ and the value of this additional unit $\left(\Delta G_{d}\right)$ are both increased. However, both a developer and the sophisticated social planner will be encouraged to develop later since both $X_{d}$ and $X_{c}$ increases as $\sigma$ increases. Given that the regulator initially taxes land value, the impact on the sophisticated social planner is even stronger.

\footnotetext{
${ }^{10}$ Here we also impose the constraint $\beta_{1 d}<1 /(1-b)$, which is required so that the option value to invest, $F_{d}(X, Q)=\int_{0}^{\infty} \Delta F_{d}(X(s), Q) d s$, will be positive.
} 
Table 3 Option value of waiting, investment value, development trigger, and optimal taxation on both land value and development when the expected growth rate of the demand-shift factor changes

\begin{tabular}{|c|c|c|c|c|c|}
\hline \multirow[t]{2}{*}{ Parameters } & \multicolumn{5}{|c|}{ Variation in $\alpha$} \\
\hline & 0 & 0.01 & 0.02 & 0.03 & 0.04 \\
\hline$\Delta F_{d}$ & 0.6099 & 0.8000 & 0.9708 & 1.2000 & 1.5165 \\
\hline$\Delta G_{d}$ & 1.8699 & 2.0000 & 2.1708 & 2.4000 & 2.7165 \\
\hline$X_{d}$ & 0.0935 & 0.0800 & 0.0651 & 0.0480 & 0.0272 \\
\hline$X_{c}$ & 0.1035 & 0.0967 & 0.0907 & 0.0856 & 0.0813 \\
\hline$u^{*}$ & $32.9 \%$ & $45.0 \%$ & $67.1 \%$ & $113.9 \%$ & $259.1 \%$ \\
\hline$\tau^{*}$ & $1.56 \%$ & $0.902 \%$ & $0.499 \%$ & $0.252 \%$ & $0.098 \%$ \\
\hline
\end{tabular}

Benchmark case: same as Table 1

Consequently, the regulator should either increase the optimal tax rate on development $\left(u^{*}\right)$ or decrease the optimal tax rate on land value $\left(\tau^{*}\right)$ to induce the developer to delay development such that the developer's timing decision matches the timing schedule chosen by the sophisticated social planner.

Consider now an increase in the expected growth rate of the demand-shift factor $(\alpha)$. For the decentralized economy, the option value of investing in an additional unit of developed property $\left(\Delta F_{d}\right)$ and the value of this additional unit $\left(\Delta G_{d}\right)$ are both increased. A developer and the sophisticated social planner will both be encouraged to develop sooner since $X_{d}$ and $X_{c}$ decrease as $\alpha$ increases. Given that the regulator initially taxes land value, the impact on the developer, however, is even stronger. Consequently, the regulator should either increase the optimal tax rate on development $\left(u^{*}\right)$ or decrease the optimal tax rate on land value $\left(\tau^{*}\right)$ to induce the developer to delay development such that the developers' timing decision matches the timing schedule chosen by the sophisticated social planner.

Furthermore, we find that the effects of a decrease in the discount rate $(\rho)$ on the endogenous variables resemble the effects of an increase in the expected growth rate

Table 4 Option value of waiting, investment value, development trigger, and optimal taxation on both land value and development when the discount rate changes

\begin{tabular}{|c|c|c|c|c|c|}
\hline \multirow[t]{2}{*}{ Parameters } & \multicolumn{5}{|c|}{ Variation in $\rho$} \\
\hline & 0.03 & 0.04 & 0.05 & 0.06 & 0.07 \\
\hline$\Delta F_{d}$ & 1.2000 & 1.0702 & 0.9708 & 0.8921 & 0.8279 \\
\hline$\Delta G_{d}$ & 2.4000 & 2.2702 & 2.1708 & 2.0921 & 2.0279 \\
\hline$X_{d}$ & 0.0240 & 0.0454 & 0.0651 & 0.0837 & 0.1014 \\
\hline$X_{c}$ & 0.0605 & 0.0759 & 0.0907 & 0.1052 & 0.1194 \\
\hline$u^{*}$ & $202.7 \%$ & $100.5 \%$ & $67.1 \%$ & $50.8 \%$ & $41.3 \%$ \\
\hline$\tau^{*}$ & $0.110 \%$ & $0.278 \%$ & $0.499 \%$ & $0.770 \%$ & $1.088 \%$ \\
\hline
\end{tabular}

Benchmark case: same as Table 1 
Table 5 Option value of waiting, investment value, development trigger, and optimal taxation on both land value and development when the tax rate on land value changes

\begin{tabular}{|c|c|c|c|c|c|}
\hline \multirow[t]{2}{*}{ Parameters } & \multicolumn{5}{|c|}{ Variation in $\tau$} \\
\hline & 0 & 0.025 & 0.05 & 0.075 & 0.1 \\
\hline$\Delta F_{d}$ & 2.0649 & 1.2814 & 0.9708 & 0.8000 & 0.6902 \\
\hline$\Delta G_{d}$ & 3.2649 & 2.4814 & 2.1708 & 2.0000 & 1.8902 \\
\hline$X_{d}$ & 0.0979 & 0.0744 & 0.0651 & 0.0600 & 0.0567 \\
\hline$u^{*}$ & $11.1 \%$ & $46.2 \%$ & $67.1 \%$ & $81.4 \%$ & $91.9 \%$ \\
\hline
\end{tabular}

Benchmark case: same as Table 1

on the demand for developed properties. We therefore do not repeat the discussion here.

Turning next to an increase in the tax rate on land value $(\tau)$, for the decentralized economy the option value of investing in an additional unit of developed property $\left(\Delta F_{d}\right)$ and the value of this additional unit $\left(\Delta G_{d}\right)$ are both decreased. However, a developer will be encouraged to develop sooner because the former will be reduced ever more than the latter, as shown in Tables $1,2,3,4,5$, and 6 , which indicate that $X_{d}$ decreases with an increase in $\tau$. Therefore, the regulator should also increase the optimal tax rate on development $\left(u^{*}\right)$ to induce the developer to choose the development timing selected by the sophisticated social planner. This also suggests that these two property taxation instruments are complementary to each other, and thus is consistent with the result of Proposition 3(c).

Finally, consider an increase in the tax rate on land development $(u)$. In contrast to changes in the tax rate on land value, for the decentralized economy the option value of investing in an additional unit of developed property $\left(\Delta F_{d}\right)$ and the value of this additional unit $\left(\Delta G_{d}\right)$ are both increased. However, a developer will be encouraged to delay development because the former is increased by a magnitude larger than the latter. Naturally, the optimal tax rate on land value $\left(\tau^{*}\right)$ is also increased as a result of an increase in the tax rate on development.

Table 6 Option value of waiting, investment value, development trigger, and optimal taxation on both land value and development when the tax rate on development changes

\begin{tabular}{|c|c|c|c|c|c|}
\hline \multirow[t]{2}{*}{ Parameters } & \multicolumn{5}{|c|}{ Variation in $u$} \\
\hline & 0 & 0.1 & 0.2 & 0.3 & 0.4 \\
\hline$\Delta F_{d}$ & 1.3660 & 1.5026 & 1.6392 & 1.7758 & 1.9124 \\
\hline$\Delta G_{d}$ & 2.3660 & 2.6026 & 2.8392 & 3.0758 & 3.3124 \\
\hline$X_{d}$ & 0.0710 & 0.0781 & 0.0852 & 0.0923 & 0.0994 \\
\hline$\tau^{*}$ & $-0.533 \%$ & $-0.058 \%$ & $0.499 \%$ & $1.156 \%$ & $1.938 \%$ \\
\hline
\end{tabular}

Benchmark case: same as Table 1 


\section{Conclusion}

This article employs a real options framework to investigate the design of taxation on both land value and development in a competitive real estate market. We assume that developed properties reduce open space, and thereby harm urban residents. However, ignoring this negative externality, landowners will develop properties sooner than is socially optimal. A regulator can correct this tendency by imposing a positive tax on development or a negative tax on land value. Alternatively, the regulator can implement these two instruments simultaneously, both of which will complement the other.

Our assumption that property development harms urban residents differs markedly from the idea of Henry George (1897), who advocates that the regulator should tax more on vacant land and less on land development. Based on Henry George's idea, Brueckner (1986) investigates how a shift to a graded tax system (where the tax rate on land development is decreased and the tax rate on land value is increased) affects the level of land development, the value of vacant land, and the price of housing in the long run. Anderson (1999) extends Brueckner's analysis to a perfect foresight model, but focuses on how this shift affects a landowner's choice of development timing. Both papers assume that a regulator collects the same amount of tax revenues when shifting the tax system. This contrasts with our analysis, as we allow tax revenues to vary when the regulator implements optimal property taxation policies. Future studies may investigate whether our theoretical results stated in Proposition 3 continue to hold when we impose constraints on tax revenues.

Acknowledgements We would like to thank the editor (Kanak Patel), two anonymous reviewers, Yeh-Ning Chen, Steven Ott, Dean A. Paxson, Brenda A. Priebe, Dogan Tirtiroglu, and participants of both the 2006 IEFA Conference and the 2006 Cambridge-UNCC Symposium for their helpful comments on earlier versions of this manuscript. Financial support under Grant NSC 95-2416-H-002-045 from the National Science Council, Executive Yuan, R.O.C., is gratefully acknowledged.

\section{Appendix A}

Differentiating $X_{d}(Q)$ in Eq. 15 with respect to $\sigma, \tau, u, \alpha$, and $\rho$ yields

$$
\begin{gathered}
\frac{\partial X_{d}(Q)}{\partial \sigma}=\frac{-(1+u)(\rho-\alpha) K Q^{1-b}}{\left(\beta_{1 d}-1\right)^{2}} \frac{\partial \beta_{1 d}}{\partial \sigma}>0, \\
\frac{\partial X_{d}(Q)}{\partial \tau}=\frac{-(1+u)(\rho-\alpha) K Q^{1-b}}{\left(\beta_{1 d}-1\right)^{2}} \frac{\partial \beta_{1 d}}{\partial \tau}<0, \\
\frac{\partial X_{d}(Q)}{\partial u}=\frac{\beta_{1 d}(\rho-\alpha) K}{\left(\beta_{1 d}-1\right)} Q^{1-b}>0,
\end{gathered}
$$




$$
\left\{\begin{aligned}
\frac{\partial X_{d}(Q)}{\partial \alpha}=\frac{(\rho+\tau)(1+u) K Q^{1-b} B}{(\rho+\tau-\alpha)} & <0, \text { if } \tau \geq 0, \\
& <0, \text { if } \tau<0,
\end{aligned}\right.
$$

and

$$
\frac{\partial X_{d}(Q)}{\partial \rho}=(1+u) K Q^{1-b}\left[\frac{\beta_{1 d}}{\left(\beta_{1 d}-1\right)}-\frac{(\rho-\alpha)}{\left(\beta_{1 d}-1\right)^{2}} \frac{\partial \beta_{1 d}}{\partial \rho}\right] \frac{>}{<} 0,
$$

$\underset{\partial \beta_{1 d}}{\text { where }} B=\frac{(\rho-\alpha)}{\beta_{2 d}^{2}} \frac{\partial \beta_{2 d}}{\partial \alpha}-\left(1-\frac{1}{\beta_{2 d}}\right) \frac{\tau}{(\rho+\tau-\alpha)}, \quad \frac{\partial \beta_{1 d}}{\partial \sigma}<0, \quad \frac{\partial \beta_{1 d}}{\partial \tau}>0, \quad \frac{\partial \beta_{2 d}}{\partial \alpha}<0, \quad$ and $\frac{\partial \beta_{1 d}}{\partial \rho}<0$.

QED.

\section{Appendix B}

Differentiating $X_{c}(Q)$ in Eq. $15^{\prime}$ with respect to $\sigma, \alpha$, a, and $\rho$ yields

$$
\begin{gathered}
\frac{\partial X_{c}(Q)}{\partial \sigma}=-\frac{(1-a)(\rho-\alpha) K Q^{1-b}}{\left(\beta_{1 c}-1\right)} \frac{\partial \beta_{1 c}}{\partial \sigma}>0, \\
\frac{\partial X_{c}(Q)}{\partial a}=\frac{-\beta_{1 c}(\rho-\alpha) K Q^{1-b}}{\left(\beta_{1 c}-1\right)}<0, \\
\frac{\partial X_{c}(Q)}{\partial \alpha}=\frac{(1-a) K Q^{1-b}}{\beta_{2 c}^{2}} \frac{\partial \beta_{2 c}}{\partial \alpha}<0,
\end{gathered}
$$

and

$$
\frac{\partial X_{c}(Q)}{\partial \rho}=(1-a) K Q^{1-b}\left[\frac{\beta_{1 d}}{\left(\beta_{1 d}-1\right)}-\frac{(\rho-\alpha)}{\left(\beta_{1 d}-1\right)^{2}} \frac{\partial \beta_{1 d}}{\partial \rho}\right] \frac{>}{<} 0,
$$

where

$$
\frac{\partial \beta_{1 c}}{\partial \sigma}>0, \quad \frac{\partial \beta_{2 c}}{\partial \alpha}<0, \quad \text { and } \quad \frac{\partial \beta_{1 c}}{\partial \rho}>0
$$

QED.

\section{Appendix C}

Equating $X_{d}(Q)$ in Eq. 15 and $X_{c}(Q)$ in Eq. $15^{\prime}$ yields

$$
M(\tau, u)=(1-a)(1+u)-\left(1-\frac{1}{\beta_{1 d}}\right)\left(1-\frac{1}{\beta_{1 c}}\right)^{-1}=0 .
$$


Suppose that $\tau=\tau^{*}$ and $u=u^{*}$ satisfy Eq. C1. Totally differentiating $\mathrm{C} 1$ with respect to $a, \sigma, \alpha, \rho$, and $u$ yields

$$
\begin{aligned}
& \frac{d \tau^{*}}{d a}=\frac{\Delta_{1}}{-\Delta}<0, \\
& \frac{d \tau^{*}}{d \sigma}=\frac{\Delta_{2}}{-\Delta} \frac{\geq}{<} 0, \\
& \frac{d \tau^{*}}{d \alpha}=\frac{\Delta_{3}}{-\Delta} \frac{>}{<} 0, \\
& \frac{d \tau^{*}}{d \rho}=\frac{\Delta_{4}}{-\Delta} \frac{>}{<} 0,
\end{aligned}
$$

and

$$
\frac{d \tau^{*}}{d u}=\frac{\Delta_{5}}{-\Delta}>0,
$$

where

$$
\begin{aligned}
& \Delta=\frac{\partial M}{\partial \tau}=\frac{-\beta_{1 c}}{\left(\beta_{1 c}-1\right) \beta_{1 d}^{2}} \frac{\partial \beta_{1 d}}{\partial \tau}<0, \\
& \Delta_{1}=-(1+u)<0 \\
& \Delta_{2}=\frac{\partial M}{\partial \sigma}=\frac{4 \beta_{1 c}\left(\beta_{1 d}-1\right)\left(\beta_{1 c}-\beta_{1 d}\right)}{\sigma \beta_{1 d}\left(\beta_{1 c}-1\right)\left(2 \beta_{1 c}-1\right)\left(2 \beta_{1 d}-1\right)}<0, \quad \text { if } \tau>0, \\
& =0, \quad \text { if } \tau=0 \text {, } \\
& >0, \quad \text { if } \tau<0 \text {, } \\
& \begin{aligned}
\Delta_{3}=\frac{\partial M}{\partial \alpha}=\frac{2\left(\beta_{1 d}-1\right) \beta_{1 c}}{\left(\beta_{1 c}-1\right) \beta_{1 d} \sigma^{2}}\left[\frac{1}{\beta_{1 d}\left(\beta_{1 d}-1\right)^{2}}-\frac{1}{\beta_{1 c}\left(\beta_{1 c}-1\right)^{2}}\right] & <0, \\
=0, & \text { if } \tau>0, \\
& >0, \quad \text { if } \tau<0,
\end{aligned} \\
& \Delta_{4}=\frac{\partial M}{\partial \rho} \\
& =\frac{2 \beta_{1 c}\left(\beta_{1 d}-1\right)}{\sigma^{2} \beta_{1 d}\left(\beta_{1 c}-1\right)}\left[\frac{1}{\beta_{1 c}\left(\beta_{1 c}-1\right)\left(2 \beta_{1 c}-1\right)}-\frac{1}{\beta_{1 d}\left(\beta_{1 d}-1\right)\left(2 \beta_{1 d}-1\right)}\right]>0, \quad \text { if } \tau>0, \\
& =0, \quad \text { if } \tau=0, \\
& <0, \quad \text { if } \tau<0 \text {, }
\end{aligned}
$$


and

$$
\Delta_{5}=\frac{\partial M}{\partial u}=1-a>0 .
$$

It is easy to prove that the effects of $a, \sigma, \alpha$, and $\rho$ on $u^{*}$ are just the opposite of those shown by Eqs. C2-C5.

QED.

\section{References}

Anderson, J. E. (1986). Property taxes and the timing of urban land development. Regional Science and Urban Economics, 16(4), 483-492.

Anderson, J. E. (1993). Land development, externalities, and Pigouvian taxes. Journal of Urban Economics, 33(1), 1-9.

Anderson, J. E. (1999). Two-rate property tax effects on land development. Journal of Real Estate Finance and Economics, 18(2), 181-190.

Arnott, R. J. (2005). Neutral property taxation. Journal of Public Economic Theory, 7(1), 27-50.

Arnott, R. J., \& Lewis, F. D. (1979). The transition of land to urban use. Journal of Political Economy, 87 (1), 161-169.

Bar-Ilan, A., \& Strange, W. (1999). Timing and intensity of investment. Journal of Macroeconomics, 21, $57-77$.

Brueckner, J. K. (1986). A modern analysis of the effects of site value taxation. National Tax Journal, 39 (1), 49-58.

Capozza, D., \& Li, Y. (1994). The intensity and timing of investment: The case of land. American Economic Review, 84(4), 889-904.

Cox, J. C., \& Ross, S. A. (1976). The valuation of options for alternative stochastic process. Journal of Financial Economics, 3(1-2), 145-166.

Dixit, A. K. (1991). Irreversible investment with price ceilings. Journal of Political Economy, 99(3), 541557.

Dixit, A. K., \& Pindyck, R. S. (1994). Investment under uncertainty. Princeton, NJ: Princeton University Press.

George, H. (1897). Progress and poverty. New York: Henry George.

Grenadier, S. R. (1995). Valuing lease contracts: A real-options approach. Journal of Financial Economics, 38(3), 297-331.

Grenadier, S. R. (2000). Equilibrium with time-to-build: A real options approach. In M. Brennan \& L. Trigeorgis (Eds.), Project flexibility, agency and competition (pp. 275-296). Oxford: Oxford University Press.

Irwin, E. G., \& Bockstael, N. E. (2004). Land use externalities, open space preservation, and urban sprawl. Regional Science and Urban Economics, 34(6), 705-725.

Jou, J.-B. (2001). Environment, asset characteristics, and optimal effluent fees. Environmental and Resource Economics, 20(1), 27-39.

Jou, J.-B. (2004). Environment, irreversibility and optimal effluent standards. Australian Journal of Agricultural and Resource Economics, 48(1), 127-158.

Lee, T., \& Jou, J.-B. (2007). The regulation of optimal development density. Journal of Housing Economics, 16(1), 21-36.

Lucas, R. E. Jr., \& Prescott, E. C. (1971). Investment under uncertainty. Econometrica, 39(3), 659-681.

McFarlane, A. (1999). Taxes, fees, and urban development. Journal of Urban Economics, 46(3), 416-436.

Pindyck, R. S. (1988). Irreversible investment, capacity choice, and the value of the firm. American Economic Review, 78(5), 969-985.

Turnbull, G. K. (1988a). The effects of local taxes and public services on residential development patterns. Journal of Regional Science, 28(4), 541-562.

Turnbull, G. K. (1988b). Property taxes and the transition of land to urban use. Journal of Real Estate Finance and Economics, 1(4), 393-403. 